\title{
USE OF FACEBOOK FOR ACADEMIC NETWORK LEARNING IN UNIVERSITAS TERBUKA - INDONESIA
}

\author{
Adhi Susilo (adhi@mail.ut.ac.id) \\ Universitas Terbuka
}

\begin{abstract}
Facebook clearly provides a social outlet for college students, a fact backed by the large membership among this peer group. Socializing, however its unintended outcomes, is part and parcel of education of the whole person. Facebook has its place in that sense, but there seems to be a lack of any compelling reason to significantly integrate it into distance education. Students could use it as a secondary information exchange outlet in a cooperative learning mode with classmates that they have invited in their space, to complete group projects, for example. The services offered through Facebook (e.g. chatting, meeting new classmates, arranging for social/academic meetings) can well be attained using the current technologies in CMSs without the risk of security breaches and other legal matters pervasive in social networking websites. The potential use of facebook for distance learning is greatest. There was a strong feeling from distance learning students that they wanted a safe, private space to communicate. They were happy for tutors to be involved because they saw this space as having a specific course purpose. The advantage over the Virtual Learning Environment is that it seems to encourage that important social interaction as well as the course based interaction. This paper discusses distance learning education and the usage of facebook, as well as the possible implementation of facebook in distance learning education courses. The traditional way of accessing and using content from the Internet is shifting to a more collaborative environment whereby individuals, especially teenagers and young adults, are using various social networking software technologies not only to create information, but in sharing it as well. Perhaps by implementing facebook in distance education courses, it may allow instructors to get to know their students better, as well as to allow for more student-to-student interactions. This paper also discusses the usage of facebook in order to extend teacher and student collaborations in creating online learning environments.
\end{abstract}

Keywords: facebook, learning network.

Facebook is an online social network software application used by university students to articulate existing offline social connections as well as forge new ones. The service constitutes a rich site for researchers interested in the affordances of social networks due to its heavy usage patterns and technological capacities which bridge online and offline connections. Like other social networking sites, such as Friendster, Tribe net and MySpace, Facebook enables its users to present themselves in an online profile, accumulate "friends" who can post comments on each other's pages, and view each other's profiles. They can also join virtual 
groups based on common interests, see what classes they have in common, and, via the profile, learn each others' hobbies, interests, musical tastes, and romantic relationship status.

Facebook was created in February 2004 by Mark Zuckerberg, a student at Harvard University. The idea for the website was motivated by a social need at Harvard to be able to identify people in other residential houses (Moyle, 2004). Today Facebook has more than 7.5 million registered members at over 2,000 U.S. colleges and is the seventh-most-popular site on the entire Web with respect to total page views (Cassidy, 2006). The site is tightly integrated into the daily media practices of its users: the typical user spends about 20 minutes a day on the site and two-thirds of them log in at least once a day (Cassidy, 2006).

Capitalizing upon the success among college students, Facebook launched a high school version of Facebook in early September 2005. In 2006, the company introduced communities for commercial organizations such as Microsoft, Amazon and PepsiCo (Barton, 2006); at the time of this writing, over 4000 organizations had created Facebook directories (Smith, 2006). Although student reception to the affordances of Facebook has been enthusiastic, popular press coverage has focused almost exclusively on the negative repercussions of Facebook use. Many of these problems stem from misalignments between users' perceptions about the audience for their profile and the actual audience. Students have been reprimanded for including racist or otherwise problematic content in their profiles and postings and for including inappropriate information that might be accessible by future employers. Although there has been substantial media coverage of Facebook, there has been little academic work exploring the phenomenon, and most of the current thinking is based on anecdotal evidence as opposed to empirical data. It is this context - large numbers of highly embedded users, a unique geographically-bound target audience, high visibility, and widespread public concern coupled with few academic studies of the site - that motivated our investigation. In contrast with other Facebook research, our focus is cases in which the intended audience and the actual audience are aligned, and what positive outcomes are associated with this kind of use.

Networked learning communities have attracted the attention of educators partly due to the growth of on-line learning. Serving to provide recommendations for practitioners who will engage in designing and developing effective learning communities, this paper synthesizes relevant literature on strategies for creating and maintaining these networked communities for distance learning. After identifying the following four important factors that influence learning in communities, that is, interactivity, opportunities for collaboration, a meaningful and motivating context, and a continuously available learning environment, the paper discusses design guidelines which are valuable in the construction of these communities. The recommendations, presented in a framework of the three major aspects involved in on-line learning, technological, social, and pedagogical, are intended to maximize and reinforce the four important factors listed above.

The use of the term 'community' has gained much higher frequency recently with respect to pedagogical theory (e.g., O'Neill, 2001). Networked learning communities (hereafter NLCs), in particular, have attracted the attention of educators partly due to the growth of on-line learning, in which the learning process is supported by interaction via a computer network (Goodyear, 
Salmon, Spector, Steeples, \& Tickner, 2001). As with traditional learning communities that are bound by physical proximity, NLCs possess the desirable features of fostering a sense of belonging and appreciation for the rituals of a group (Noddings, 1996). As well as these traditional factors, there are additional advantages to learning in networked communities that are unavailable with the traditional, non-technologically-enhanced classrooms.

Providing recommendations for designers and developers of learning communities, this paper first discusses these advantages, as they are outlined in relevant literature in the field of distance learning, and then explores what are seen as three aspects, i.e., technological, social, and pedagogical, of the development of effective distance learning.

\section{SOCIAL NETWORK AND THE INTERNET}

A social network service focuses on building online communities of people who share interests and activities, or who are interested in exploring the interests and activities of others. Most social network services are web based and provide a variety of ways for users to interact, such as e-mail and instant messaging services (http://en.wikipedia.org/wiki/Social_network, 2008). Social networking has created powerful new ways to communicate and share information. Social networking websites are being used regularly by millions of people, and it now seems that social networking will be an enduring part of everyday life. The main types of social networking services are those which contain directories of some categories (such as former classmates), means to connect with friends (usually with self-description pages), and recommender systems linked to trust.

There is little academic work examining online social networks. A 2005 survey of academic community members found that $90 \%$ of the undergraduates participated in a social network community, primarily Facebook, MySpace, and Friendster, and that many of them disclosed personal information such as email address (Stutzman, 2006). In her ethnographic work examining self-presentation and social connections among Friendster users, Boyd (2004) notes that users have a variety of motivations for using the site, including connecting with old friends, meeting new acquaintances, dating, and furthering professional networks. In one of the few pieces to examine this new breed of online fora, Donath and Boyd (2004) point out that one of the chief hallmarks of these sites is that links between individuals are mutual, public, unnuanced and decontextualized. In the sites that Donath and Boyd examine, public displays of connections serve to warrant, or signal the reliability of, one's identity claims. Social networking sites are distinguished from the first wave of virtual community sites in that they allow for both maintenance of existing social ties and formation of new connections.

A hallmark of the early research on computer-mediated communication and virtual communities in particular is the assumption that individuals using these systems would be connecting with those outside their pre-existing social group or location, liberating individuals to form communities around shared interests, as opposed to shared geography (Wellman et al., 1996). However, some online community researchers have explored how online communities present opportunities for people in a common offline community to extend their interaction. Such a theme is articulated by Wellman et al. (1996), who note that "Although CSSNs [computer supported social networks] do transcend time and space, not all ties are 
either totally on-line or off-line. Much on-line contact is between people who see each other in person and live locally". Nonetheless, when online and offline social networks overlapped, the direction was typically online to offline - online connections that resulted in face-to-face meetings. For instance, Rheingold (2000) discusses members of the online WELL community getting together for picnics. Today's online social networking sites are different in that they are structured to both facilitate meetings with new individuals as well as maintain existing ties. However, there have been no empirical studies to date that measure the extent to which members use these online social networking sites to maintain existing ties or to form new ones.

This issue is certainly true for geographically-based social networking sites such as Facebook, which may exemplify an understudied offline to online trend. Facebook distinguishes itself from other online social networks in that it primarily serves a geographically bound community (the campus) and by the fact that, at least for the college and university version of Facebook , membership is restricted to those with a specific host institution email address. In this sense, it is similar to the wired Toronto neighborhood studied by Keith Hampton and Barry Wellman (2003). Their work supports the view that information technology may enhance place-based community and facilitate the generation of social network. As in the "Netville" community studied by Hampton and Wellman, Facebook members share more offline connections and are more likely to anticipate meeting one another in offline spaces. In other contexts, anticipated face-to-face interaction has been shown to increase the honesty of self-presentational messages (Gibbs et al., 2006). Facebook may therefore necessitate a different set of research questions due to the fact that participants will be less likely to play with their identities (and therefore to verify others') due to the geographically bound nature of the site.

The existing academic research on Facebook has focused on identity presentation and privacy concerns (Stutzman, 2006) or analysis of the network structure (Hamatake et al., 2005). Looking at the amount of information Facebook participants provide about themselves, the relatively open nature of the information, and the lack of privacy controls enacted by the users, Gross and Acquisti (2005) argue that users may be putting themselves at risk for attacks on both offline (such as stalking) and online (such as identify theft). While the apparent schism between Facebook users' imagined audience and the actual audience, in conjunction with the highly public nature of the presentation, are cause for concern, we believe an equally important research question concerns the question of whether Facebook users are able to capitalize on the networking capacities of Facebook. Donath and Boyd (2004) hypothesize that online social networking sites may not increase the number of strong ties a person may have, but could greatly increase the weak ties one could form and maintain because the technology is wellsuited to maintaining these ties cheaply and easily. As they write, "If this is true, it implies that the technologies that expand one's social network will primarily result is an increase in available information and opportunities - the benefits of a large, heterogeneous network" (Donath \& Boyd, 2004). However, this argument has yet to be tested. We adopt the social network lens as a way to determine whether these sites are actually associated with increases in useful connections, information and opportunities. 


\section{BENEFITS OF FACEBOOK IN OPEN DISTANCE LEARNING}

Putnam (2000) concludes that one of the main causes of the decrease in social network is the long-term decrease in participation in voluntary associations like the Elks club or bowling leagues. Some researchers have claimed that online interactions may supplement or replace those interactions that previously were formed in voluntary organizations (Wellman et al., 2001). Since online relationships may be supported by technologies like recommender systems, distributions lists, photo directories and search capabilities (Resnick, 2001), it is possible that new forms of social network and relationship building might occur in online sites like Facebook. This kind of participation is closely linked to bridging social network and might be augmented by the sites like Facebook, which support loose social ties, allowing users to create and maintain larger, diffuse networks of relationships from which they could potentially draw resources (Donath \& Boyd, 2004).

In Putnam's (2000) view, bonding social network reflects strong ties with family and close friends, who might be in a position to provide emotional support or access to scarce resources. Williams (2006) points out that little empirical work has explicitly examined the role of the Internet on bonding social network, although some studies have questioned whether the Internet supplements or supplants such strong ties. Quan-Haase and Wellman (2004) review the literature on the Internet's impact on social network and categorize the extant literature into three main arguments: the Internet transforms social network (by providing individuals with the means by which to find others with similar interests, to the detriment of established offline communities); the Internet diminishes social network (by attracting people away from existing offline social networks); and the Internet supplements social network (by blending into and supporting existing social relations as well as facilitating new ones). It is evident that the Internet facilitates new connections: the Internet provides people with an alternative way to connect with individuals that share their interests (Horrigan, 2002) or to identify new romantic partners (Ellison et al., 2006). These new connections may result in an increase in social network; for instance, a 2006 Pew Internet survey reports that online users are more likely to have a larger network of close ties than non-Internet users and that Internet users are more likely than non-users to receive help from core network members (Boase et al., 2001). However, it is unclear how social network formation occurs in a context in which online and offline connections are closely coupled, as with Facebook. Williams (2006) argues that although researchers have examined potential losses of social network in offline communities due to increased Internet use, they have not adequately explored online gains that might compensate for this.

\section{Important Factors That Influence Learning in Distance Learning}

Graziadei (1996) mentioned, "One of the most important aims in education is to introduce the student to the process of inquiry and contemporary tools used to access people and information". Facebook appears to be highly valuable for the realization of these goals by offering highly interactive environments that facilitate collaboration and meaningful learning. Facebook has important factors that influences learning in distance learning: interactivity, closed collaboration, interesting context, and a sustainable learning environment, and a new opportunity for innovation. 


\section{Interactivity}

Interactivity is regarded as a key factor in on-line learning environments (Northrup, 2001). However, unlike traditional class interaction, which usually follows a sequential discourse pattem, e.g., "initiation-reply-evaluation" (Levin, Riel, Miyake, \& Cohen, 1987), on-line discussions allow multiple topics upon which communication can proceed (Black, Levin, Mehan, \& Quinn, 1983). This multiple interactive structure facilitates the pedagogical function of interaction on the part of all members of the learning communities (Rice-Lively, 1994). What is most important for our purposes is the way in which the group dynamics of interactive, networked, learning communities are seen as desirable for educational philosophies that emphasize student-centered as opposed to teacher directed learning.

\section{Closed Collaboration}

Collaboration among network community members is essential to knowledge development (Bruffee, 1999). Through enhanced collaboration, learners become involved in learning activities that are associated with a social network, which provides them with greater motivation and opportunity to articulate, discuss, and reflect on their learning strategies and the changes within themselves. NLCs, which stress the importance of distributed expertise (Lin et al., 1995), is an ideal site for collaborative learning. Not only is learner expertise highly diverse in many of these communities, but the learner population in general, the geographical locations and cultural backgrounds of community members, can also be quite diverse. The vast potential for extensive collaboration that is enabled by learning networks helps to prepare learners for life long learning in the 21st century (Harasim, 1996).

\section{Interesting Context}

Knowledge is always situated in and embedded from the context in which it is learned and used (Brown, Collins, \& Duguid, 1989). Learning cannot be adequately facilitated, therefore, solely by introducing learners to prototypical or decontextualized concepts, even when they are well defined. As electronic networks make it increasingly possible for students to approach real-life problems in authentic global settings, network communities are able to offer progressively meaningful contexts for project-based and problem-based learning (Levin et al., 1989). Networked communities also create "audience effects" (Levin \& Thurston, 1996), which make the learning context especially inspiring and motivating.

\section{Sustainable Learning Environments}

Location-independence and asynchronicity are two distinctive attributes of NLCs (Shrivastava, 1999). Continuously available learning contexts expand educational access to more people, especially the individuals who cannot afford or are otherwise unable to participate in full-time study. The removal of the constraints on place and time enables the participation in distance education programs of non-traditional students, particularly those with disabilities (Kim et al., 2001). In addition, as continuous learning comes to be seen more and more as a necessity for almost everyone in our rapidly changing and increasingly global society, the demand for more flexible educational environments increases accordingly. Negroponte (1995) points out that living in a digital age "will include less and less dependence upon being in a specific place at a specific time". By means of NLCs, the field of education is able to adapt to the rapidly changing face of communication in technologically advanced societies. 


\section{A new opportunity for innovation}

In a policy paper published by the European Open and Distance Learning Liaison Committee, it was noted that "a new vision of ICT [Information Communication Technology] for learning is needed at policy, management and grass roots practice level if a new window of opportunity is to be found for ICT to become really interesting to innovators in the learning system".

Furthermore, a new policy paper published in May 2006 identified "the knowledge gap on learning innovation" as a major problem (European ODL LC 2004 and 2006). From the perspective of ICT a new vision and a wide-open window of opportunity can be found in the current development and usage of Social Software based low-barrier and easy-to-use tools and services (Wikis, Weblogs, social networking, bookmarks and content sharing, RSS-based content syndication, podcasting, etc.) that are highly supportive of open learning practices and processes. The attribute "social" stems from the fact that such tools and services in particular promote connections, exchanges and collaboration among people who share common goals and interests. It is also acknowledged that Social Software fosters bottom-up development of communities of interest and practice, whereas typical institutional IT systems represent a topdown approach with centralised information access, authoritative information, defined user roles and permits.

Social Software is increasingly being used outside the commercial domain and shows the first spillover effects within the realm of education. Wider adoption for educational and lifelong learning purposes could have an enormous innovative impact as these tools and services are ideally suited to learner-centred as well as collaborative approaches in developing competences required in our knowledge society. Outside the educational sector the use of Social Software has reached more than a "critical mass"; it is exploding. In April 2006, the socalled "blogosphere", which is tracked by Technorati on a regular basis, amounted to 35.3 million individual Weblogs, 60 times more than in 2003. The number of Weblogs doubles about every six months, with an average of over 75,000 new Weblogs created every day. (www.technorati.com, 2006) From an educational perspective, it is understood that Weblogging is a self-directed, constructive as well as inherently conversational practice. Students who author a Weblog, which is possible individually and as a group, must make their minds up about certain topics, gather, evaluate and interpret information, take a position, come up with convincing arguments and evidence, and find the right means and style of expression. Teachers who integrate Weblogs into online and hybrid courses will find that this promotes student engagement and achievement.

The blogosphere and Wikipedia, the world's flagship in collaborative authoring with millions of articles in many languages, clearly demonstrate an important point: Social Software has made it possible for anyone to participate actively as an author in the knowledge society.

\section{RECOMMENDATIONS FOR CREATING AND MAINTAINING EFFECTIVE FACEBOOK FOR NETWORK LEARNING COMMUNITIES}

The extent to which technological advances in communication are able to enhance the convenience, and subsequently the effectiveness of educational programs depends upon the careful planning of learning activities and the adequate design of learning environments. In this 
section, recommendations, based on research findings, are provided for students and teachers of distance learning. These recommendations are presented in a framework according to what are seen as the three major aspects of the successful construction of network learning communities: technological, social, and pedagogical.

\section{Technological Aspects}

Internet as one of the information technology has recently had a great impact on the ongoing design, development, and implementation of educational paradigms. The internet has shattered the boundaries of traditional educational institutions and has made it possible for the formation of regional, national, and even global learning communities. Nevertheless, availability and access to this new technology are the only basic requirements for the construction of these communities. To make these communities highly effective as tools for learning, certainly, demands more. Students need to be made to feel comfortable with the technology and with the mode of communication so that they can concentrate on learning.

The ultimate goal for educational designers, therefore, is to make the technology as "obvious" as possible (Berge, 1995). The primary recommendations concerning the technological aspects of the development of effective facebook are as follows:

1. Provide safety access to the technology that fits the needs of the community. Safety access is the initial requirement for establishing an interactive, networked community.

2. Provide adequate technical training and support. In order for learners to master the technical skills required for participation in these communities, training and support are necessary. It is suggested, therefore, that users make the best possible use of on-line communication features so as to facilitate collaboration in a learning environment.

There are three important aspects a system would need to take in and to prove that facebook are more valuable when used continuously throughout a course as an integral part of the learning experience, as opposed to a reporting mechanism used after the main body of learning is completed:

$>$ Reflection - the student can map out his or her thoughts on a course, a piece of work, or more general experiences.

$>$ Communication - the student can communicate his or her reflections to other students, staff, tutors and lecturers.

$>$ Sharing - the student can give selected other users access to their digital objects. Learning is not as effective in isolation; there is a great deal of discussion involved in traditional courses, and this would need to be reflected in any electronic learning aid.

The importance of linking together people, ideas and resources cannot be overestimated. Facebook is a great reflective tool. A student can write something about their course, perhaps categorise it in terms of subject or the piece of work concerned, and that reflection can be accessed and searched by both date and context. However, facebook functionality comes into its own when mixed with social networking, as with LiveJournal: the student can then mark certain reflections as being for public consumption, or viewable by certain groups of other users. They can then make comments and perhaps add their thoughts in their own journals, with a link between the two established via a trackback. Students then have use of not just 
their own reflections, but those of their peers, and potentially teaching staff too: a much wider realm of thought, which might produce conclusions a student may not have arrived at on their own. A student could then, within a facebook post or portfolio page, provide a link to any object in their digital repository. Perhaps a trackback link could be made from that object to all the posts and pages mentioning it. This would allow a student or tutor to instantly see, when looking at a piece of work, the personal reflections and inter-student discussions relating to it. Furthermore, it can also affect learning in the "real world"; through a social networking enabled system, a student could find and communicate with a number of like-minded individuals, who might then organise study or social groups. If an establishment's system was linked to other systems in other parts of the country (or the world), groups of students doing similar courses could all compare notes and learn from each other.

\section{Public Aspects}

In order to develop and maintain the coherence and unity of a learning community, designers need to be aware of and implement the factors that have been proven to intensify social relations among community members. The recommendations for shortening social distance and creating social solidarity are as follows:

1. Enforce rules for interaction. Rules usually evolve with the development of a learning community, and communication of the rules, such as the issue of honesty, helps to provide a discussion space safe for community members. It is recommended that users identify prevalent rules in networked learning communities, negotiate these rules with the learners that are involved, subsequently modifying them if need be in accordance with majority opinion, and then try to enforce them throughout the communal processes of interaction.

2. maintain group identity while recognizing individual differences. It is important to help learners in a community to see themselves as part of a group in which they share similar interests. Learning communities emphasize the importance of distributed expertise, which brings different perspectives and adds variety to a group. These two emphases may appear somewhat contradictory at first glance, but it is both possible and necessary to maintain a balance between group unity and individual diversity. For instance, users may plan activities which highlight the similarity of the learners or the learning tasks in which they are engaged, and, at the same time, stress the importance of contributions of heterogeneous ideas.

3. offer appropriate coordination and support. To socialize learners into a networked community and to make the community effective for learning requires both proper structures for facilitating interaction and social support. The provision of interaction, which should be neither too much nor too little, be tailored to specified learning outcomes.

4. Deep learning: "...learning that promotes the development of conditionalized knowledge and metacognition through communities of inquiry, this can further enhance with the advent of 'knowledge rooms', areas of cyberspace that allow students to collaborate" (http://teachopolis.org/library/deep_learning.htm). The use of facebook to promote deep learning is really interesting - deep learning reflects a greater, more complex understanding of a subject. Some argue "the experience of deep learning better equips the learner to excel in future learning opportunities because the learner can discern both familiar patterns and critical variations in entirely new surface conditions. Thus, learning at both the individual and collective level involves coming to see familiar phenomena in new 
ways, 'thereby widening the world we experience" (http://www.unca.edu/et/br110698.html). The combination of facebook and weblogs may have immense benefits for the learner. These tools and the ethos behind them enhance the prospect for deep learning. Creation of a learning landscape where learners engage in the whole process both academically and socially should increase the opportunity to build one's learning instead of just being the recipients of information. This ability to engage with other learners, pull in information from various resource sources, share thoughts and feelings, form communities of learning or social activity, interact with peers and tutors within one or more institutions, would create a milieu promoting user engagement and we feel, in turn, a level of deeper learning.

\section{Academic Aspects}

Academic aspects are critical for distinguishing learning communities from other networked communities. Learning communities need to reflect their educational purposes and the paradigm of social learning that is employed, in order to successfully facilitate collaborative activities and active participation. Taking academic considerations into account in the process of design maximizes the benefits that can be attained through the utilization of the telecommunication medium. Some academic recommendations are as follows:

1. Distinguish the learners. As active participants rather than passive recipients, learners should be given opportunities for individual development based on their own expertise and experiences.

2. Design learning activities that stimulate collaborative efforts. To make sure that proposed collaborative activities are implemented and concluded on the networks, it is recommended that users, at the planning stage, acquire a certain degree of knowledge about the target participation sites, in addition to a general familiarity with the characteristics of learners. Such knowledge helps users develop activities that accommodate the needs of different learners in different settings or at different sites.

3. Be flexible on learning content and objectives. The effectiveness of a learning community relies on the selection of authentic topics for exploration, discussion, and reflection. Because learning communities are established on the assumption that learning is a constructive process, learning content and objectives should be negotiated, along with the learning process itself, rather than set in stone in advance. The precise learning content should emerge based on learners' interests and the nature of group interaction. In a learning community that allows for a high degree of flexibility with respect to learning content, support from teachers or other experts should be provided in order to guarantee the efficacy of the learning model employed.

\section{Beneficial Characteristics of Facebook}

Facebook is one of the hottest things happening right now. So what makes Facebook special from other social networking sites like Friendster and MySpace? One of the major strengths of the new look facebook is the clean layout and the simplifying of the profile page. The Profile has been divided up into tabs so that all the personal information is in one place and all the applications are on one tab now called boxes. Facebook have integrated the wall and the minifeed into one aggregated feed that takes up $70 \%$ of the space on the profile page. This major prominence is because facebook has always been designed to focus on creating and maintaining real relationships and building a sense of community. Facebook has made the 
sharing of videos and photos even easier with one dedicated tab and a host of new features to play around with. Facebook have brought in a lot of new features that help to make facebook the pivotal part of daily life. They have introduced a new blog subscription service where you can join your favourite blog and enjoy all its content without ever having to leave facebook. Another nice feature is the ability to create a profile badge that you can place on your website or blog that can show your current status and act like a business card and pull people from outside of facebook to become your friends. To access this feature you can find a link on the bottom left of your profile page. The Notes feature has increased in prominence, which is great because it gets more people involved in conversations. Anyone who has a blog can import their posts automatically and then tag their friends to come and make a comment. This runs straight into the wall feed and you can make comments directly on your wall/minifeed and keep updated on the topic without having to go back to the post and scroll down to the bottom each time a new person makes a comment.

\section{CONSTRAINT IN USING FACEBOOK FOR OPEN DISTANCE LEARNING IN OPEN UNIVERSITY OF INDONESIA}

Distance learning is not just a move away from learning within the classroom. It is a complete paradigm shift - a change in the fabric and culture of education. It is based on the premise that students are at the centre of the learning process, take responsibility for their own learning, and work at their own pace, and in their own place. It is about ownership and autonomy. Good communication in the traditional classroom setting has always been at a premium. When delivering learning materials outside the classroom across any distance, it is all the more important that technologies and techniques support learners and improve communications between students and teachers. Course delivery into remote rural communities compounds the matter still further. Barriers of cultural differences and resistance to change present as many problems as the need to effectively communicate with others at a distance. The establishment of robust delivery and support systems is therefore vital. To achieve these aims a multi-layered delivery system has been established, utilising established technologies such as personal computer and telephone communications networks, combined with the newer technologies, such as digital transmission systems and associated hardware.

The emergence of the Internet and related networks such as the World Wide Web has had and will increasingly have radical effect on the transformation of education and training in all sectors. The impact is already significant in all developed countries, and the great majority of developing countries are despite difficulties and fears seeking to take part in the emerging global educational community.

The Facebook offers a worldwide forum in which to teach courses that can be dynamically updated in ways never before possible. Each student has an enormous range of resources available, free from limitations of time and space. There remains considerable work to be done concerning searching and sifting techniques within these resources for learners and teachers alike. These resources are reconfiguring the ways in which students learn, and new approaches to networked learning are evolving. 
The trans-cultural nature of the Facebook also creates problems of legislative and public control, with fears that local culture can be threatened by the international culture of developed countries. While the use of the Facebook in open and distance learning is predominantly represented within higher education, it is also beginning to be used in schools.

It is recognized that in Indonesia access to the Web in local schools is limited. However, the Web may provide an important resource for teacher education institutions and agencies and centres that provide professional development to teachers in the country. In countries with limited access to technology infrastructure radio, television and print-based materials are used to address teacher education needs.

The University of Terbuka (UT), the Indonesian Open Learning University, was established in 1984 and remains the only single mode distance education university in the country. UT aims at providing flexible inexpensive education, reaching people unable to attend face-to-face education, increasing access to higher education, providing training in areas demanded by economic and cultural development, and upgrading the qualifications of primary and secondary school teachers.

The credibility of distance education in Indonesia is reflected in the increasing numbers of enrollments (500,000 in 700 courses) at UT, the establishment of distance education programmes in other institutions, and the establishment of the Indonesian Distance Learning Network (IDLN) to share training, research and information. With its headquarters in Jakarta, supported by 37 regional offices, UT uses both centralized and decentralized management approaches and collaborates with external institutions such as the national postal services, Bank Rakyat Indonesia, and provincial governments. Print materials developed by course teams remain the main medium of instruction while conventional examinations, self-tests, course practicums and micro-teaching make up the basis of student assessment.

Facebook is the well-known social network tools in internet have attracted many students and lecturers in Universitas Terbuka to join in their online communities. The open and distance learning system implemented in Universitas Terbuka (UT) requires students to do self-learning, individually or in groups. Therefore, the students of UT must be able to motivate themselves to self-study and use their time effectively. The use of integrated learning media as one of the learning resources can support them in their learning activities. The use of internet, as a part of e-Learning, is one way for students to perform learning activities. Nowadays, most of the students of UT are not familiar with the internet because some problems in students, for example: cost, technology, availability, accesibility, culture and computer literacy. The challenge in the use of internet by students is to make them aware of the importance of information technology in enhancing teaching and learning. Internet is not luxurious good and it is very important for them to obtain important, up-to-date and accurate information.

One of problems faced by institution which carries out long distance learning system is lack interaction between students with lecturer. Therefore, facebook which is used by students and lecturers in UT provides academic networking and interaction media for each others. Students can ask questions about administrative and academic matters to lecturers, and they can share 
their experiences and complain using facebook. Participation and problem solving attempts provided evidence of active student learning. Instead of simply using the tutors to do their homework, many students made initial attempts at solutions, queried tutor responses, and applied the help they received to make progress on solving problems. This behaviour appeared to be influenced by the actions of the tutor. Tutors provide solution and ask direct questions to students which is encouraged dialogue, whereas providing complete solutions seemed to have the beneficial effect for academic network.

There is no single answer to the question 'which technology is best?' Indeed, one starting point for choosing technologies is to recognise that media do not differ in their effectiveness. Of course a particular subject, or a particular kind of learning, may lend itself to a particular medium; print is not ideal for learning the pronunciation of an unfamiliar language and following a radio programme is not the easiest way to learn how to strip a carburettor. But a long line of research, and much practical experience, has shown that where you can compare different media for teaching the same subject matter, there are no significant differences in teaching effectiveness between different them (Clark 1983). Intuitive views about the superiority or inferiority of any one medium need to be treated with caution. There is experience of using radio for teaching mathematics, for example, while it has been seen as having advantages over television for some approaches to teaching art: you cannot see teacher's painting and copy it. The result is that we can choose our technologies on grounds such as their appropriateness, convenience and cost, reassured that many different combinations of technology are likely to be effective. There is some evidence to suggest that combinations of media are likely to be more effective than any single medium. Practicalities buttress this argument: if something is available both on the radio and in print then you have an alternative if you miss the radio programme or if the printed document does not arrive. A careful blend of media, drawing on their individual strengths and minimising their individual limitations, is likely to produce the best results.

\section{CONCLUSION}

Network learning communities have not only been incorporated into traditional distance education programs, but also become prevalent in facilitating on-campus courses. Within the new type of on-line learning environments, the establishment of cohesive and effective NLCs in which learners build upon each other's expertise to succeed is crucial. In pursuing the goal of building learning communities that inspire and enable learners to acquire new information resources, adopt new roles, and build new relationships, in order to survive in the technologyrich global society, this paper has examined factors, in particular, that have an especially profound influence on pedagogical effectiveness. The design recommendations that have been provided help to maximize the positive influence of the three major aspects involved: technological, social, and pedagogical. It is hoped that these recommendations will assist facebook users in the development of effective networked learning communities that benefit learners.

The strong linkage between Facebook use and open distance learning connections suggests how online social networks help maintain relations as people move from one offline community to another. It may facilitate the same when students graduate from college, with alumni 
keeping their school email address and using Facebook to stay in touch with the college community. Such connections could have strong payoffs in terms of jobs, internships, and other opportunities. Colleges may want to explore ways to encourage this sort of usage. Facebook's users are using the online channel less to meet new people than to intensify and solidify relationships that started offline.

The main benefit of the facebook arising from the process rather than the product. The learning landscape created by fusing facebook and weblogs, network learning communities will be further enhance this process. During the process of network learning communities construction and reflection the information one has sinks in to a deeper level meaning the learner is not relying on memory but rather deep routed knowledge - if this process of construction is more compelling for the learner through their desire to engage due to functionality like social networking the phrase 'power in the process' takes on even more meaning. This would be a shame as the potential could be far greater. It is allowing the management of material and creation of public interfaces but also an opportunity for reflection, engagement and the formation of communities of learning and socialising providing a means to promote deep learning.

\section{REFERENCES}

Barton, Z. (2006). Facebook goes corporate. CNET.

Black, S.D., Levin, J.A., Mehan, H. \& Quinn, C.N. (1983). Real and non-real time interaction: Unraveling multiple threads of discourse. Discourse Processes, 6 (1), 59-75.

Boase, J., Horrigan, J.B., Wellman, B., \& Rainie, L. (2001). The strength of internet ties. Washington, D.C.: Pew Internet and American Life Study.

Boyd, D. (2004, April 24-29, 2004). Friendster and publicly articulated social networks. Paper presented at the Conference on Human Factors and Computing Systems (CHI 2004). Vienna.

Brown, J.S., Collins, A., \& Duguid, P. (1989). Situated cognition and the culture of learning. Educational Researcher, 18(1), 32-42.

Bruffee, K.A. (1999). Collaborative learning: Higher education, interdependence, and the authority of knowledge. (2nd ed.). Baltimore, MD: The Johns Hopkins University Press.

Cassidy, J. (2006, May 15, 2006). Me media. The New Yorker, 50- 59.

Clark, R.E. 1983 'Reconsidering research on learning from media', Review of educational research

Donath, J., \& Boyd, D. (2004). Public displays of connection. BT Technology Journal, 22 (4), 71.

Ellison, N., Heino, R., \& Gibbs, J. (2006). Managing impressions online: Self-presentation processes in the online dating environment. Journal of Computer-Mediated Communication, 11(2), article 2. http://jcmc.indiana.edu/vol11/issue2/ellison.html

Goodyear, P., Salmon, G., Spector, J.M., Steeples, C., \& Tickner, S. (2001). Competences for online teaching: A special report. Educational Technology Research and Development, 49 (1), 65-72.

Graziadei, W.D. (1996). VICE in REST. In T. M. Harrison \& T. Stephen (Eds.), Computer networking and scholarly communication in the twentyfirst-century university (pp. 257276). New York: State University of New York Press. 
Gross, R., \& Acquisti, A. (2005). Information revelation and privacy in online social networks. Paper presented at the WPES'05, Alexandria, Virginia, USA.

Hamatake, N., Lifson, D., \& Navlakha, S. (2005). The facebook: Analysis of a Cornell community social network. Retrieved December 2, 2005 from http://www.people.cornell.edu/pages/nh39/papers/cs685.pdf

Hampton, K., \& Wellman, B. (2003). Neighboring in netville: How the internet supports community and social network in a wired suburb. City \& Community, 2(4), $277-311$.

Harasim, L. (1996). Online education: The future. In T. M. Harrison \& T. Stephen (Eds.), Computer networking and scholarly communication in the twentyfirst-century university (pp. 155-136). New York: State University of New York Press.

Horrigan, J. B. (2002). Online communities: Networks that nurture long-distance relationships and local ties. Washington, D.C.: Pew Internet and American Life Study.

http://en.wikipedia.org/wiki/Social_network. retrieved June 15, 2008.

http://teachopolis.org/library/deep_learning.htm, retrieved July 1, 2008

http://www.unca.edu/et/br110698.html, retrieved July 5, 2008

Kim, R., W.S., Dowrick, P.W., \& Burke, L.S. (2001). Implications for improving access and outcomes for individuals with disabilities in postsecondary distance education. American Journal of Distance Education, 15 (1), 25-40.

Levin, J. A., Riel, M., Miyake, N., \& Cohen, M. (1987). Education on the electronic frontier: Teleapprentices in globally distributed educational contexts. Contemporary Educational Psychology, 12, 254-260.

Levin, J.A., Rogers, A., Waugh, M., \& Smith, K. (1989). Observations on electronic networks: Appropriate activities for learning. The Computing Teacher; 16, 17-21.

Levin, J.A., \& Thurston, C. (1996). Educational electronic networks: A review of research and development. Educational Leadership, 54(3), 46-50.

Lin, X., Bransford, J. D., Hmelo, C. E., Kantor, R. J., Hickey, D. T., Secules, T., Petrosino, A. J., Goldman, S. R., \& the Cognition and Technology Group at Vanderbilt. (1995). Instructional design and development of learning communities: An invitation to a dialogue. Educational Technology, 35(5), 53-63.

Moyle, K. (2004). Internet helps people connect with past friends. University Wire. Parks, M. R., \& Floyd, K. (1996). Making friends in cyberspace. Journal of Computer-Mediated Communication, 1(4).

Negroponte, N. (1995). Being digital. New 'eork: Vintage Books.

Newby, G.B. (1993). The maturation of norms for computer-mediated communication. Intemet Research, 3(4), 30-38.

Newman, D. (1990). Cognitive and technical issues in the design of educational computer networking. In Harasim, L. (Ed.), Online Education (pp. 99-116). NY: Preager.

Noddings, N. (1996). On community. Educational Theory, 46(3), 245-267.

Northrup, P. (2001). A framework for designing interactivity into web-based instruction. Educational Technology, 41(2), 31-39.

O'Neill, D.K. (2001). Knowing when you've brought them in: Scientific genre knowledge and communities of practice. Journal of the Leaming Sciences, 10(3), 223-264.

Palloff, R.M., \& Pratt, K. (1999). Building leaming communities in cyberspace: Effective strategiesfor the online classroom. San Francisco: Jossey-Bass Publishers. 
Quan-Haase, A., \& Wellman, B. (2004). How does the internet affect social network? In M. Huysman \& V. Wulf (Eds.), Social capital and information technology (pp. 113-135). Cambridge, MA: MIT Press.

Resnick, P. (2001). Beyond bowling together: Sociotechnical capital. In J. Carroll (Ed.), HCl in the new millennium: Addison-Wesley.

Rheingold, H. (2000). The virtual community: Homesteading on the electronic frontier. Cambridge, MA: The MIT Press.

Rice-Lively, M.L. (1994). Wired warp and woof: An ethnographic study of a networking class. Intemet Research, 4(4), 20-35.

Riel, M. (1989). Four models of educational telecommunications: Connections to the future. Education \& Computing, 5, 261-274.

Shneiderman, B. (1989). Reflections on authioring, editing, and managing hypertext. In E. Barrett (Ed.), The society of text: Hypertext, hypermedia, and the social construction of information (pp. 115-131). Cambridge, MA: The MIT Press.

Shrivastava, P. (1999). Management classes as online learning communities. Joumal of Management Education, 23(6), 691-702.

Smith, Justin. (2006) 4,000 companies have created Facebook directories. Retrieved June 9, 2006, from Inside Facebook Web site: http://www.insidefacebook.com/?p=15

Stutzman, F. (2006). An evaluation of identity-sharing behavior in social network communities. Paper presented at the iDMAa and IMS Code Conference, Oxford, Ohio.

Wellman, B., Haase, A.Q., Witte, J., \& Hampton, K. (2001). Does the internet increase, decrease, or supplement social network? Social networks, participation and community commitment. American Behavioral Scientist, 45.

Wellman, B., Salaff, J., Dimitrova, D., Garton, L., Gulia, M., \& Haythornthwaite, C. (1996). Computer networks as social networks: Collaborative work, telework, and virtual community. Annu. Rev. Social., 22, 213-238.

Williams, D. (2006). On and off the 'net: Scales for social network in an online era. Journal of Computer-Mediated Communication, 11(2), article 11.

http://jcmc.indiana.edu/vol11/issue2/williams.html 